Is too much testing bad for student performance and well-being?

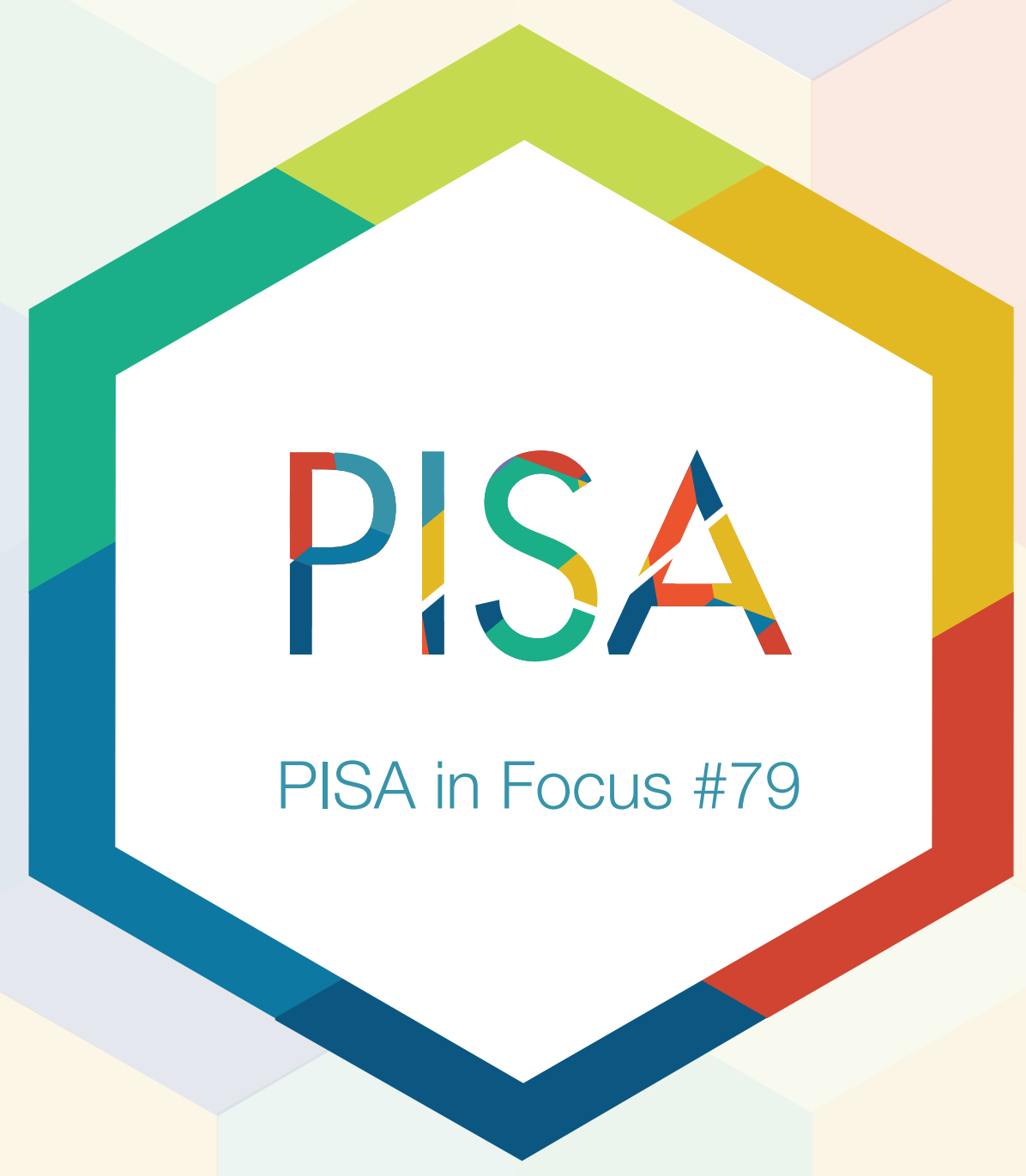




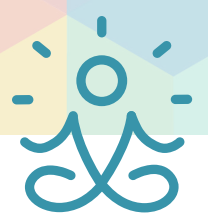

\section{Is too much testing bad for student performance and well-being?}

- On average, $70 \%$ of students attend schools where standardised tests are never used or used only once or twice a year. At the same time, more than $60 \%$ of students are evaluated by teacher-developed tests and ratings at least once a month.

- Test-related anxiety is widespread: $59 \%$ of students worry about taking a test, and $66 \%$ worry about getting poor grades.

- Neither test anxiety nor science performance is related to the frequency of testing.

Standardised tests help measure student's progress at school and can inform education policy about existing shortfalls. However, too much testing could lead to much pressure on students and teachers to learn and teach for a test, something that would take the joy out of the learning process.

Many parents and educators are all too familiar with this quandary: they recognise that good measurement can drive improvement, but often argue that too much testing can make students anxious without improving their learning. In particular, standardised tests that determine the academic and life pathways of students may trigger anxiety, and if conducted too frequently might lead to poorer performance, absenteeism and lower self-confidence. But are standardised tests really used all that frequently? And what do the data show about the relationship between performance, anxiety and the frequency of testing?

\section{Standardised tests are not used as frequently as many believe.}

PISA 2015 collected data on the frequency of testing in the grade typically attended by 15-year-olds and on students' feelings of anxiety. The data show that mandatory and non-mandatory standardised tests are not used as often as teacher-developed tests. On average across OECD countries, about 25\% of 15-year-old students attend a school where mandatory standardised tests are never used, and 60\% attend schools where these tests are used only once or twice a year. In 11 countries, including Belgium, Costa Rica, Germany, Slovenia and Spain, more than 50\% of students are in schools that never assess students with mandatory standardised tests, while in Sweden and the United Kingdom, all students sit these tests at least once during that school year (e.g. GCSEs in England). Non-mandatory tests are used less frequently than mandatory tests, but teacher-developed tests and judgemental ratings are used considerably more frequently. On average across OECD countries, about 30\% of students sit teacher-developed tests every month and 38\% sit these tests more than once a month. In Belgium, Canada, France, the Netherlands, Singapore, Spain and Chinese Taipei, more than 50\% of students sit teacher-developed tests more than once a month.

Interestingly, in the United States, where the debate about standardised testing originated, less than 30\% of students are in schools that conduct mandatory tests three or more times per year - a smaller proportion than in 19 other education systems.

PISA data also show that test-related anxiety is widespread. On average, around $59 \%$ of students reported that they worry about taking a test, $66 \%$ worry about getting poor grades, 55\% worry about tests even when they are well prepared, $52 \%$ get nervous when they fail to solve a task at school, and $37 \%$ get tense when they study for a test. 
Frequency of assessments at school

Percentage of students in schools where the following assessments are used, OECD average

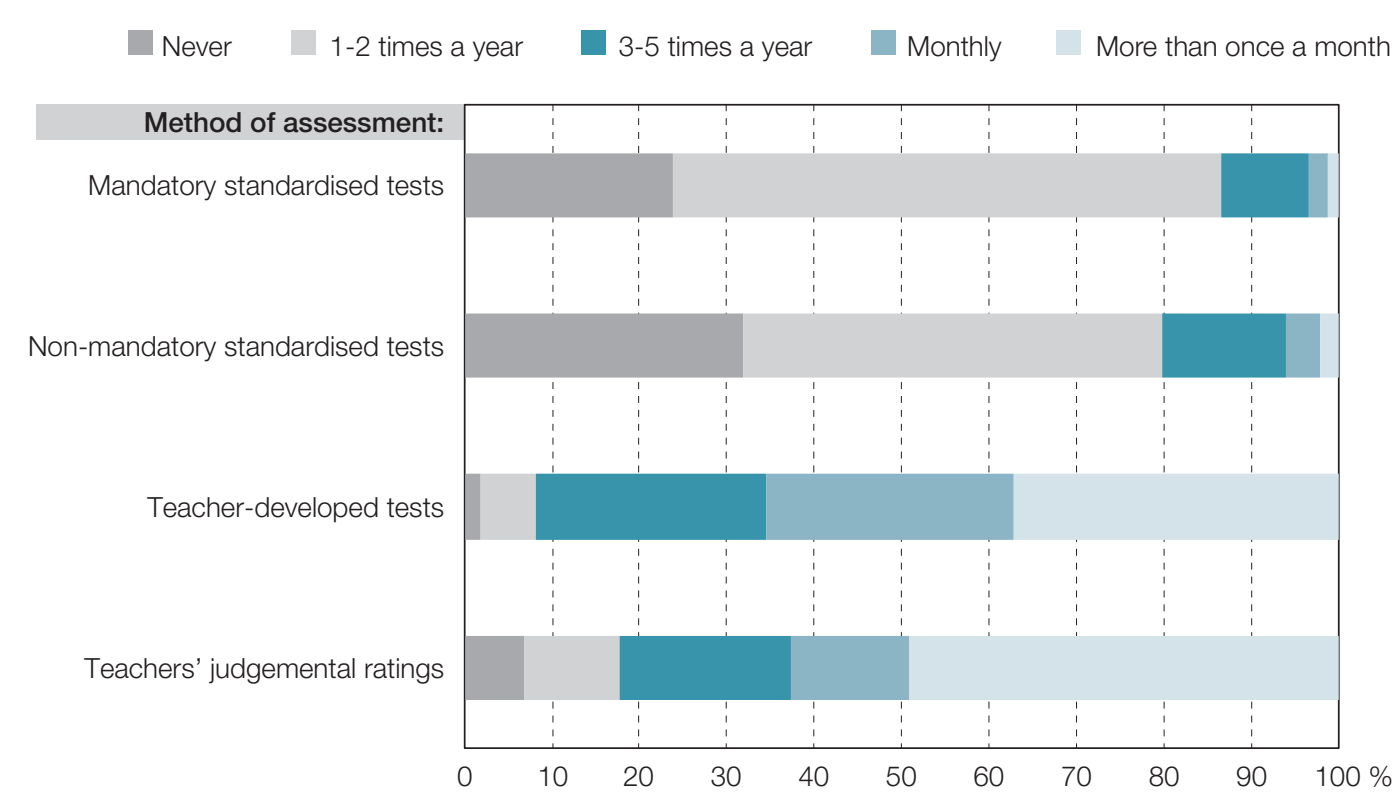

Source: OECD, PISA 2015 Database, Table II.4.19.

StatLink 제네 $\mathrm{http}: / / \mathrm{dx}$. doi.org/10.1787/888933435972

Prevalence of schoolwork-related anxiety, by gender

Percentage of students who reported that they "agree" or "strongly agree" with the following statements, OECD average

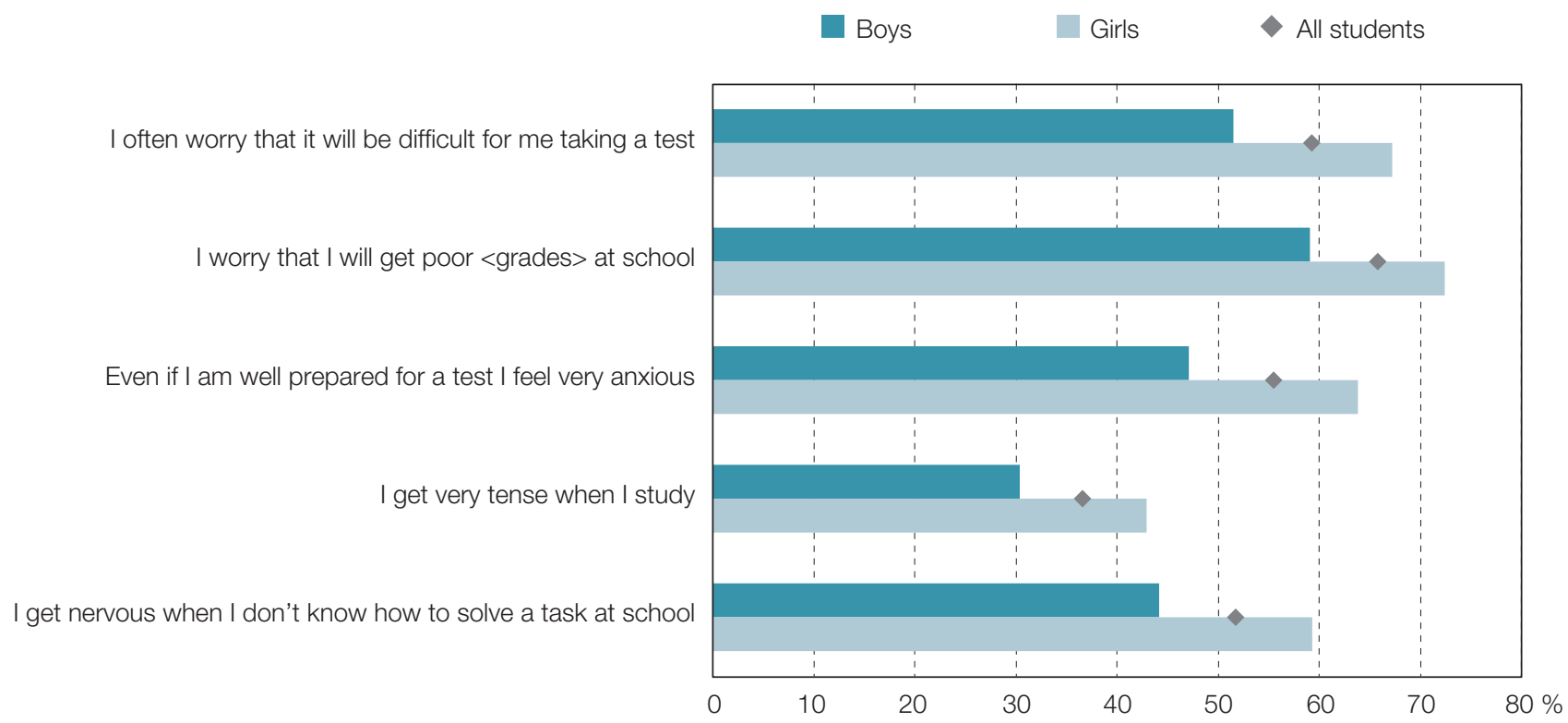

Note: All gender differences are statistically significant (see Annex A3 in OECD (2016), PISA 2015 Results (Volume II), OECD Publishing, Paris). Source: OECD, PISA 2015 Database, Tables III.4.1, III.4.2 and III.4.5.

StatLink त्ञाजा http://dx.doi.org/10.1787/888933470845 


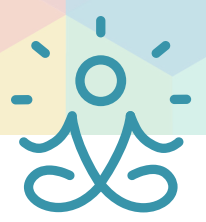

\section{Students' anxiety towards tests has little to do with the frequency of testing.}

Contrary to commonly held beliefs, the frequency of tests, as reported by school principals, is not related to the level of test anxiety reported by students. In fact, on average across OECD countries, students who attend schools where they have to sit standardised or teacher-developed tests at least once a month reported similar levels of test anxiety as students who attend schools where assessments are conducted less frequently.

One possible explanation is that test anxiety is triggered by aspects of the tests other than their frequency. For instance, the nature or difficulty of the task, the surrounding atmosphere, time constraints, characteristics of the examiner, the mode in which the test is conducted, and the physical setting of the test might influence students' psychological attitudes towards the test. All of these factors, in turn, interact with the students' own ability, self-confidence, motivation, study and test-taking skills, and preparation.

The relationship between performance in science and the frequency with which schools or countries assess students is also weak. On average across OECD countries, students who are assessed with mandatory standardised tests at least once a year score slightly lower in science (by six points) than those who are assessed more frequently, while students who are assessed with teacher-developed tests at least once a month score somewhat higher (by five points) than those who are assessed less frequently. But after accounting for students' and schools' socio-economic profile, these associations are not significant.

A country's performance in PISA is also unrelated to the use of standardised testing. Among countries and economies that perform near the top in science, the use of mandatory standardised tests is widespread in Beijing-Shanghai-Jiangsu-Guangdong (China), Singapore and the United Kingdom, but relatively uncommon in Germany, Korea and Switzerland.

\section{Type of assessments at school, science performance}

Correlations at the system level

\begin{tabular}{l|c|c}
\multirow{2}{*}{\multicolumn{1}{c|}{ Type of assessments at school, science performance }} & Across OECD countries & Across 64 countries and economies \\
\cline { 2 - 3 } Mandatory standardised tests at least once a year & Science performance & Science performance \\
\hline Non-mandatory standardised tests at least once a year & 0.05 & 0.12 \\
\hline Teacher-developed tests at least once a month & -0.04 & 0.15 \\
\hline
\end{tabular}

Note: The correlation coefficient varies between -1 and 1 and indicates the existence of a linear association between two measures. Values close to 0 indicate the lack of a linear association; values close to 1 indicate a strong positive relationship; values close to -1 a strong negative relationship. Values that are statistically significant are indicated in bold (see Annex A3 in OECD (2016), PISA 2015 Results Nolume II), OECD Publishing, Paris).

Source: OECD, PISA 2015 Database.

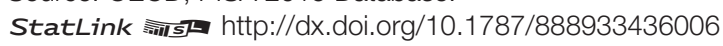

\section{Students are less anxious about tests when they feel supported by teachers and parents.}

Other aspects of students' school experience have a stronger relationship with their likelihood of feeling anxious than the frequency with which they are assessed. PISA shows that students reported less anxiety when their teachers provide more support or adapt the lessons to their needs. In contrast, students reported greater anxiety when they feel that their teachers treat them unfairly, such as by grading them harder than other students, or when they have the impression that their teachers think they are less smart than they are. 
Teachers' practices and students' schoolwork-related anxiety

Likelihood that students feel anxious for a test even if they are well prepared or get very tense when they study associated with teachers' practices

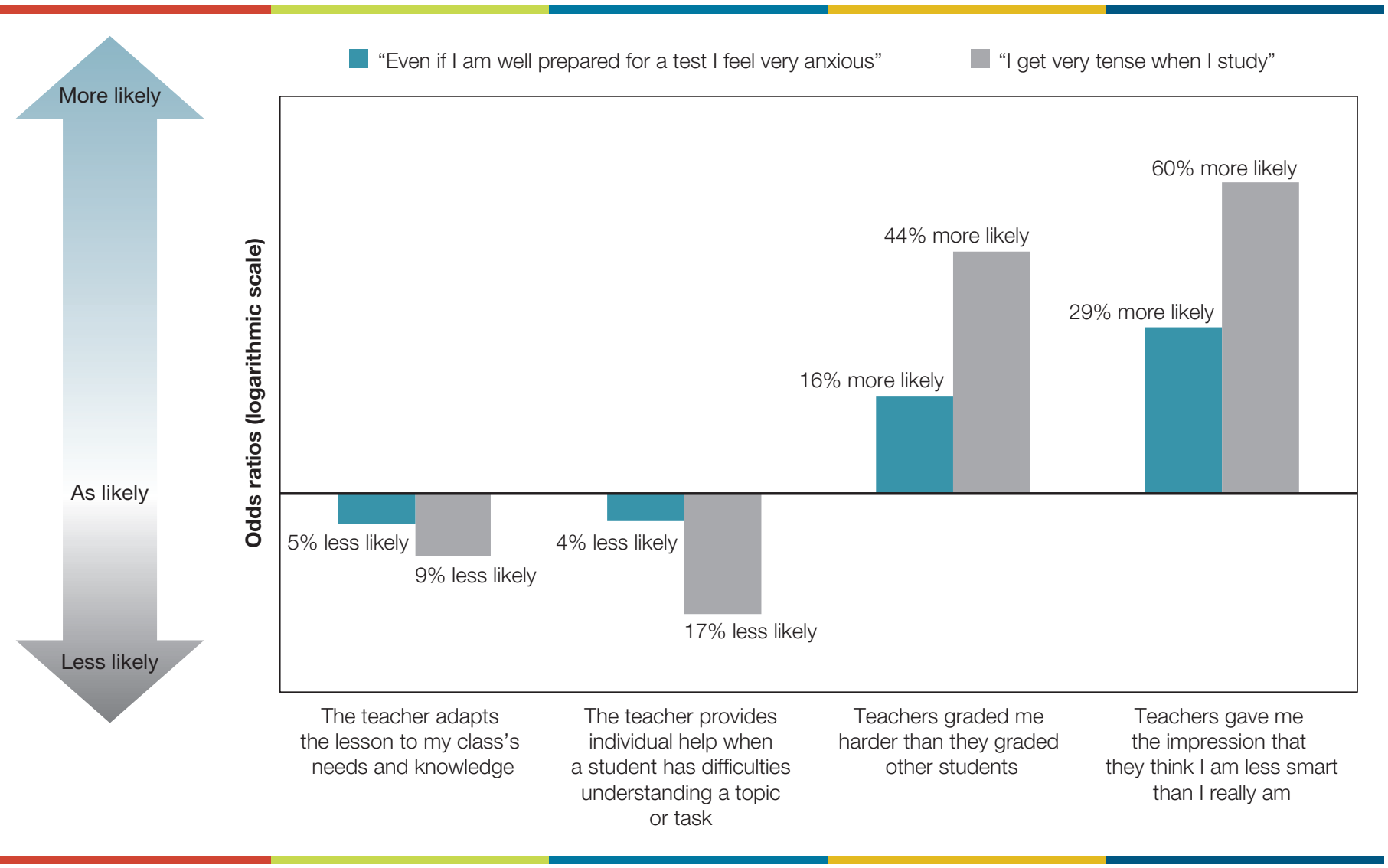

Note: The values account for students' differences in the PISA index of economic, social and cultural status (ESCS) and performance in science. All values are statistically significant.

Source: OECD, PISA 2015 Database, Table III.4.11.

StatLink 게대 http://dx.doi.org/10.1787/888933470882

Positive relations with parents are also important. Parents can help their children overcome anxiety by encouraging them to trust in their ability to accomplish academic tasks. For instance, girls who reported that their parents encourage them to be confident reported much less anxiety, even after accounting for differences in performance and socio-economic status (this relationship was found to be weaker among boys). In contrast, putting too much emphasis on test scores and setting unrealistic goals only increase anxiety.

\section{The bottom line}

Standardised and teacher-developed tests play an important role in monitoring student performance and academic progress. When students perceive that their teachers treat them fairly, and that their parents and teachers help them build their self-confidence and set realistic goals, they are less likely to feel anxious when confronted with a test. 


\section{For more information}

Contact: Tarek Mostafa (Tarek.Mostafa@oecd.org)

See: OECD (2016), PISA 2015 Results (Volume II): Policies and Practices for Successful Schools, OECD Publishing, Paris, http://dx.doi.org/10.1787/9789264267510-en.

OECD (2017), PISA 2015 Results, Nolume III): Students' Well-Being, OECD Publishing, Paris, http://dx.doi.org/10.1787/9789264273856-en.

Coming next month: What do science teachers find most satisfying about their work?

This paper is published under the responsibility of the Secretary-General of the OECD. The opinions expressed and the arguments employed herein do not necessarily reflect the official views of OECD member countries.

This document, as well as any data and map included herein, are without prejudice to the status of or sovereignty over any territory, to the delimitation of international frontiers and boundaries and to the name of any territory, city or area.

This work is available under the Creative Commons Attribution-NonCommercial-ShareAlike 3.0 IGO (CC BY-NC-SA 3.0 IGO). For specific information regarding the scope and terms of the licence as well as possible commercial use of this work or the use of PISA data please consult Terms and Conditions on www.oecd.org. 